\title{
Trabalho, reestruturação do capital e mercado de trabalho em Macaé
}

Labor, capital restructuring and labor market in Macaé

Paula Martins Sirelli,* Ranieri Carli de Oliveira, ${ }^{* *}$
Keyla Marques Campos,

\begin{abstract}
Resumo: $O$ artigo aborda a reestruturação do capital e seus impactos na cidade de Macaé. A mesma se destaca por abrigar a Petróleo Brasileiro S/A (PETROBRAS) desde 1978, abarcando mudanças econômicas e sociais substancias para a cidade e a região. O texto enfoca o desenvolvimento desigual e combinado, resultado das opções políticas e econômicas. Focaliza o mercado de trabalho formal, a partir de dados da RAIS, numa pesquisa bianual de 1990 a 2010. Concluímos que apesar de um estrondoso aumento de vínculos formais nos últimos 20 anos, os mesmos não vêm sendo acompanhados por uma qualidade destes vínculos, fortalecendo a tese de uma renovada precarização das relações formais de trabalho, sobre sólidas bases de exploração, alienação e aumento da extração do mais valor, ancorada em práticas como a flexibilização dos vínculos, intensificação do trabalho e terceirização da força de trabalho.
\end{abstract}

Palavras-chave: mercado de trabalho; precariedade salarial; Petróleo Brasileiro SA. (PETROBRAS); Macaé.

\begin{abstract}
This article addresses the restructuring of capital and its impact on the city of Macaé. This city stands out for harboring PETROBRAS since 1978, embracing important economic and social changes for the city and the region. The text focuses on the uneven and combined development, a result of political and economic options. Focuses on the formal labor market, based on data from the RAIS, a biennial
\end{abstract}

\footnotetext{
* Assistente Social, doutoranda do Programa de Pós-Graduação em Serviço Social da Universidade do Estado do Rio de Janeiro (PPGSS/UERJ), e professora assistente do curso de Serviço Social da Universidade Federal Fluminense/Polo Universitário de Rio das Ostras - UFF/ PURO. Correspondência: Rua Recife, s/n, Jardim Bela Vista, CEP: 28890-000. Rio das Ostras/RJ. Email: <paulasirelli@yahoo.com.br>.

** Cientista social, doutor em Serviço Social pela Universidade Federal do Rio de Janeiro (UFRJ), professor adjunto do curso de Serviço Social da Universidade Federal Fluminense/Polo Universitário de Rio das Ostras - UFF/ PURO. E-mail: <raniericarli@gmail.com>.

*** Graduanda em Serviço Social da Universidade Federal Fluminense/Polo Universitário de Rio das Ostras - UFF/PURO. Bolsista PIBIC. E-mail: <keylamcampos@yahoo.com.br>.

**** Graduanda em Serviço Social da Universidade Federal Fluminense/Polo Universitário de Rio das Ostras - UFF/PURO. E-mail: <heloajsilva@bol.com.br>.
} 
survey from 1990 to 2010. We conclude that despite a huge increase in formal employment in the last 20 years, they are not being accompanied by a quality of those links, reinforcing the thesis of a renewed deterioration of formal relations work on areas of solid bases of exploitation, alienation and increasing of extracting surplus value, anchored in practices as the labor flexibilization, intensification of labor and workforce outsourcing.

Keywords: labor market; precarious salary; PETROBRAS; Macaé.

\section{Introdução}

Refletir acerca do mercado de trabalho e das novas configurações do capital na cidade de Macaé tem se colocado como uma questão prioritária e urgente. O potencial dos benefícios para o desenvolvimento local decorrente da exploração do petróleo nas ultimas três décadas ainda está para ser avaliado. Nossa preocupação, enquanto professores, moradores e pesquisadores da região, é construir um estudo acerca da realidade de Macaé que traduza o impacto socioeconômico, político e social da Petróleo Brasileiro S/A (PETROBRAS) nestas últimas décadas, refletindo sobre as condições de vida dos seus habitantes, inserção no mercado de trabalho e tipos de vínculos destes contratos. Há uma lacuna na bibliografia acerca do mercado de trabalho nos últimos anos na região, historicamente vital para o entendimento da realidade (uma vez que as crises que vem ocorrendo rebatem na cidade e a realização de análises sobre esta realidade faz-se necessária para, inclusive, permitir qualificadas formas de intervenção sobre ela). Autores renomados da chamada "sociologia do trabalho" reforçam o caráter imperativo de se conhecer o mercado de trabalho no que tange a compreensão da dinâmica regional:

É preciso conhecer a dinâmica do mercado de trabalho, ou seja, quais são os segmentos da força de trabalho, seu grau de expropriação e as possibilidades de integração na dinâmica econômica regional; e identificar quais são as atividades econômicas capazes de mobilizar a força de trabalho e promover a sua inserção enquanto produtora de riqueza, através da sua organização e do provimento dos meios para tal - crédito, conhecimento, técnica, instrumentos de trabalho, informação, políticas públicas urbanas e de bem-estar. (CRUZ, 2011, s/ p.).

Pretendemos com esta pesquisa responder ao nosso compromisso ético e político com a universidade pública e seu processo de interiorização, no que diz respeito à necessidade de compreender, analisar a realidade local e de dar respostas às problemáticas que se colocam no cotidiano peculiar da região. Por certo, esta responsabilidade se espraia para todas as categorias profissionais; no entanto, chamamos a atenção para a especificidade dos 
assistentes sociais, uma vez que se apresenta com urgência para esta categoria compreender as novas configurações que o capitalismo impõe à força de trabalho, na tentativa de desencobrir o processo de exploração e alienação em suas modalidades contemporâneas, com vistas a qualificar a intervenção profissional junto a este segmento. Nos seus diversos níveis, cabe à formação profissional ampliar as possibilidades de qualificação, visando a identificação de novas demandas advindas de formas contemporâneas de precarização do trabalho, construindo possibilidades de produção de conhecimento e intervenção sobre tais condições de vida e de produção dos trabalhadores, garantindo-Ihes acesso aos direitos sociais e melhoria da qualidade de vida e trabalho. Daí a razão pela qual precisam ser ampliadas pesquisas sobre a referida temática, até mesmo em um instante histórico em que o desenvolvimento do capitalismo regional ganha novos contornos, quando estão em cena discussões contemporâneas e importantes sobre o uso e distribuição dos royalties. Entretanto, diga-se que as pesquisas elaboradas que não sejam apenas um exercício de exegese acadêmica, mas de explicação e intervenção nos espaços contraditórios das relações produtivas, considerando-se as características locais que traduzem a "nova precariedade salarial" (ALVES, 2011) e a "precarização estrutural do trabalho". (ANTUNES, 2010).

Na perspectiva de ter como solo da reflexão teórica a realidade, a pesquisa apreende a experiência da precariedade salarial do trabalho em Macaé e seus impactos no mercado formal de trabalho, utilizando os dados da Relação Anual de Informações Sociais (RAIS), a partir do ano de 1990, data inicial da implantação da Reforma Gerencial do Aparelho do Estado. As variáveis foram pesquisadas levando-se em conta o recorte geográfico (município de Macaé) e pelos setores de atividades estabelecidos pelo IBGE, quais sejam: extrativismo mineral, indústria de transformação, serviços industriais de utilidade pública, construção civil, comércio, serviços, administração pública e agropecuária.

Tendo em vista este recorte, foram somados a eles as variáveis: número de vínculos, gênero, faixa etária, grau de instrução, faixa de remuneração, faixa de hora contratada e tamanho de estabelecimento. Todas as informações foram extraídas de todos estes setores e estão arquivadas para possíveis pesquisas. Os dados, entretanto, só foram analisados na totalidade dos setores. Após os dados coletados, os mesmos foram organizados por temáticas e sintetizados - apenas a síntese está exposta aqui, mas todas as tabelas estão disponibilizadas para consulta no site do Observatório do TrabaIho em Macaé ${ }^{1}$, entendendo que certamente alimentarão futuras pesquisas e o planejamento de políticas públicas voltadas para o trabalho. Após esta sistematização e organização em forma de tabelas, foram construídos gráficos das sínteses das tabelas (em forma de linha e coluna). Os dados quantitativos foram analisados pelos pesquisadores (professores e alunos) inten-

1 Conferir em <http://www.puro.uff.br/observatoriodotrabalho $>$. 
sivamente em confronto com as categorias apreendidas da bibliografia estudada, à luz do referencial teórico utilizado. Este esforço de aproximação teórica ao objeto de estudo é sintetizado aqui.

A bem dizer, a pesquisa se fundamenta na teoria social marxista, cujo princípio metodológico elementar é o recurso da crítica, para que se situem os dados quantitativos na perspectiva da totalidade da produção capitalista, particularizada no período e na região analisados. Deste modo, o dado estatístico adquire conteúdo histórico, apresentando-se como a manifestação de relações sociais da economia capitalista.

\section{Macaé - a terra prometida?}

Macaé é uma cidade situada na Região Norte Fluminense que, segundo dados do último senso (2010), detém uma população de 206.748 habitantes. Na década de 1970, a então chamada "princesinha do Atlântico" passa a ser reconhecida como a "capital brasileira do petróleo". A instalação da PETROBRAS na cidade em 1978 trouxe novas configurações para a estrutura produtiva da cidade e do seu entorno. A pesca e a agropecuária deixaram de ser o alicerce da economia. Sua estrutura produtiva passa a ser marcada pela absorção de força de trabalho inserida na área petrolífera, o que acarreta um processo de rearranjo econômico, político, demográfico e territorial. Em seu entorno, cresce uma miríade de empresas, algumas multinacionais e prestadoras de serviços, dando à cidade uma nova configuração (SILVA; CAVENAGHI, 2011).

A indústria offshore arrebatou mudanças e possibilidades de condições para reestruturação da base econômica e social da cidade. Campos dos Goytacases, centro produtivo na região até a década de 1970, vai perdendo sua função como polo atrativo de emprego na área sucroalcooleiro para Macaé. Este processo traz novos contornos para a estrutura migratória e de emprego na região, bem como uma nova dinâmica de desenvolvimento econômico. Esta transição das atividades da indústria sucroalcooleiro, predominantemente rural, dá lugar a atividades ligadas à indústria de petróleo, atividade urbana, tendo como centro dinâmico a cidade de Macaé. (PAGANOTO, 2008).

Esta significativa mudança é percebida nos indicadores populacionais. Se compararmos o crescimento populacional de Macaé nas quatro últimas décadas, nos deparamos com os seguintes números, reveladores de um crescimento populacional exponencial em todas as décadas, mas com ênfase na última - 56\%. Em 1980, Macaé detinha uma população de 75.863 habitantes, 100.695 em 1991, 132.461 nos anos 2000, e 206.748 no último senso realizado em 2010.

Ao analisar os números de crescimento populacional comparativamente às cidades do norte fluminense, Macaé apresenta uma taxa de 


\section{ReVistg all pantg}

\} TRABALHO, REESTRUTURAÇÃO DO CAPITAL E MERCADO - SIRELLI, P. M.; OLIVEIRA, R. C.; CAMPOS, K. M.; SILVA, H. J. \}

crescimento maior que as demais cidades da região: Campos cresceu 13,9\%; Carapebus, 54\%; Cardoso Moreira, 0,4\%; Conceição de Macabu, 12,9\%; Quissamã, 48\%; São Fidelis, 2,1\%; São Francisco de Itabapoana, 0,5\%; São João da Barra, 18,4\% e Macaé, 58,1\%.

Macaé apresenta um aumento em $58 \%$ de sua população se comparado ao último censo (2000), crescimento muito superior à média do estado do Rio de Janeiro $(11,1 \%)$ e a do Brasil (12,3\%). Este crescimento populacional reforça a tese de que muitas pessoas procuram Macaé e seu entorno (além das cidades supracitadas, o crescimento de Rio das Ostras e Cabo Frio é emblemático desta situação) em busca de uma "terra prometida" (promessa bíblica de que Deus concederia aos descendentes dos patriarcas hebraicos Abraão, Isaac e Jacó uma terra onde pudessem ser livres e criar suas famílias, desde que continuassem tementes a Deus. Nossa comparação com Macaé deve-se ao fato de muitos depositarem na cidade uma expectativa de liberdade, melhores condições de vida, trabalho, emprego, renda e moradia, enfim, uma expectativa de poder gozar das riquezas desta terra, do mesmo modo como fizeram os personagens bíblicos, como se pode conferir no Antigo Testamento).

Estes números revelam um aumento da demanda por emprego na região; como resposta a esta circunstância, tem-se uma grande absorção desta força de trabalho pelo mercado local de trabalho. Os dados coletados por nós, referentes ao número de vínculos de 1990 a 2010, mostram como Macaé caminha no sentido de um crescimento do mercado formal de trabalho se comparada a municípios como Campos ou até mesmo ao cenário estadual e nacional. Este dinamismo revela a extinção de empregos ligados a antigas atividades de predominância na região (LIMA; SANTOS; RODRIGUES, 2011), como a agropecuária, fabricação têxtil e transporte ferroviário.

A história da educação nos diz que os processos de instauração de novas modalidades industriais exigem que, na mesma medida, a formação da força de trabalho atenda a estas novidades tecnológicas (CARLI, 2010). Quanto ao nosso assunto, determinadas pesquisas apontam exatamente para uma exigência de qualificação, o que nos leva a investigar se os trabalhadores de Macaé (ex-empregados em setores como a agropecuária) respondem a este perfil; ou se esta é uma das causas do grande número de migrações para o município, como descrito na pesquisa de Paganoto (2008, p.6), cujos resultados enumeram 35.304 migrantes apenas na década de 1990.

Aqueles migrantes com qualificação técnica para trabalhar no ramo do petróleo ou nas atividades diretamente ligadas a ele conseguem emprego com certa facilidade, recebem salários acima da média regional e estimulam um processo de especulação imobiliária no vetor de expansão sul do município. Ao mesmo tempo, os migrantes sem qualificação ou não conseguem empregos ou ficam subempregados, engrossando os bolsões de pobreza que crescem em ritmo acelerado, principalmente nas áreas ao norte do Rio Macaé e nas imediações 
do Parque Nacional da Restinga de Jurubatiba. O crescimento da mancha urbana da cidade baseada na expansão destes dois vetores principais, ao sul - essencialmente constituído por população de alta renda - e ao norte - de população majoritariamente de baixa renda -, mostra o aprofundamento de um nítido processo de segregação sócio-espacial.

Configuram-se, nestas condições, enclaves de modernidade, a exemplo dos condomínios exclusivos e bairros nobres, conectados à sociedade local pela exploração de uma mão-de-obra numerosa e barata, que atua, por exemplo, nos serviços domésticos e nos da construção civil.

Como se deduz da passagem transcrita, muitos trabalhadores procuram a região na certeza de encontrar um novo "eldorado", a "terra prometida". Contudo, a "terra prometida" não se comprova para amplas camadas da classe trabalhadora. Fatos recentes veiculados pela mídia nacional mostram uma favelização da cidade, e, acompanhado do aumento da pobreza, o aumento da criminalidade e do tráfico de drogas como expressões da questão social, tão palpáveis no capitalismo contemporâneo (GLOBOTV, $2011)^{2}$.

O município apresenta sobrecarga nos serviços de utilidade pública, congestionamento em horários de pico, falta d'água em bairros periféricos, enchentes constantes, escassez crescente de moradia, favelização acelerada e uso predatório do litoral, além de outras mazelas que uma ocupação industrial sem planejamento acarreta nos locais em que se fixa. (PAGANOTO, 2008, p. 6).

À luz de Cruz (2002, s/p.), entendemos que um dos fatores contribuintes para o desigual desenvolvimento econômico e social de Macaé (ressaltamos que não é o único), consiste na limitação do processo de produção do petróleo.

Um dos aspectos que condicionam os estreitos limites da geração de trabalho e renda na economia do Norte Fluminense diz respeito ao fato de o complexo de petróleo limitar-se à extração. O petróleo sai do fundo do mar para os oleodutos que o transportam até as unidades de beneficiamento e distribuição, fora da região, as empresas de serviços a essas atividades, altamente especializados que concentram os recursos desse setor, são em maioria estrangeiras ou sediadas fora da região, em grandes centros nacionais, como São Paulo. Não houve internalização de etapas de beneficiamento da cadeia produtiva do

\footnotetext{
${ }^{2}$ GLOBOTV. BOPE vai ficar por tempo indeterminado nas comunidades Nova Holanda e Malvinas. Bom Dia Rio. Disponível em: <http://globotv.globo.com/rede-globo/bom-dia-rio/v/bopevai-ficar-por-tempo-indeterminado-nas-comunidades-nova-holanda-e-malvinas/1468842/l>. Acesso em: 25 mar. 2011.
} 
petróleo no Norte Fluminense, limitando os efeitos a montante e a jusante da atividade, ou a difusão espacial e social dos seus benefícios. Isto explicaria o limite alcance regional dos seus impactos e a concentração dos mesmos em Macaé.

Podemos associar a não internalização da cadeia produtiva de petróleo em Macaé à iniciativa da reestruturação produtiva que tem como pressuposto a redução de custos. A exemplo disto podemos observar a "epidemia" das empresas terceirizadas que deslocam postos de emprego, enfraquecendo a dinâmica de contratação no município. As vagas de emprego disponíveis exigem um trabalhador flexível, polivalente e qualificado.

Este dado chama a atenção para a redução de atividades ao extrativismo, uma vez que limita expansão e diversificação do mercado de trabalho. Corrêa Borba, Moura Oliveira e Silva Neto (2007) fazem uma análise da influência do petróleo na dinâmica econômica de Macaé e de Aberdeen (Reino Unido). As duas cidades apresentaram dinâmicas de crescimento semelhantes, tendo no petróleo uma estratégia de soerguimento do capitalismo.

"Na condição de recurso natural não renovável o petróleo é finito, e torna-se cada vez mais escasso em função da demanda crescente de energia no mundo" (CORRÊA BORBA; MOURA OLIVEIRA; SILVA NETO, 2007, p. 1). Assim, é previsível o fim do ciclo do petróleo na Bacia de Campos (onde se insere Macaé) e, por consequência, impactos no mercado de trabaIho e na estrutura social da cidade (como ocorreu em Aberdden, uma drástica redução dos níveis de emprego).

Apesar de se erguer uma estrutura pública estatal para dar aporte ao desenvolvimento sustentável da região, principalmente após a aprovação da Lei dos Royalties em 1985, a gestão e uso destes recursos para tal fim são muito questionadas - culminando inclusive no questionamento da própria lei. Cruz $(2011$; 2003) defende que a distribuição dos royalties constitui uma forma de canalizar recursos financeiros para a administração municipal, formando um novo bloco de poder nas novas elites regionais de administradores municipais que gerem as rendas petrolíferas.

Os royalties significavam, antes de qualquer coisa, uma fonte permanente de recursos que não as tradicionais, que eram setoriais, dirigidas e monopolizadas por grupos sociais minoritários e utilizadas de forma pouco distributiva em termos territoriais, econômicos e sociais, e totalmente reguladas, em fluxo e volume, pelas relações entre as elites agroindustriais e as autoridades federais reguladoras da atividade. Mas, acima de tudo, eles significavam a mudança do controle dos recursos estratégicos. E, a partir de 2000, com um salto impressionante no volume do royalties [...], acrescido das participações especiais, os municípios se consolidam, definitivamente, como os atores locais e regionais com maior poder de fogo financeiro para dinamizar a economia regional. (PAGANOTO, 2008, p. 26 - grifos no original). 
Como a Lei n. 9.478/1997 (BRASIL, 1997) não apresenta determinada rigidez para com o controle do destino a ser dado ao recurso recebido pelo município, a saber, os royalties, os gestores ficam livres para escolher como utilizar tal recurso. Essa questão implica diretamente na disparidade que há entre o desenvolvimento econômico e social nos municípios da região.

Os recursos advindos dos royalties poderiam ter como destino a implementação de políticas públicas que assegurassem qualidade de vida da população. Outro destino possível seria a utilização destes recursos como suporte das políticas fiscais e monetárias que dão sustentáculo ao desenvolvimento do capital financeiro, além das empresas multinacionais da região.

lamamoto (2010) ressalta que: "[...] os dois braços em que se apoiam as finanças - as dívidas públicas e o mercado acionário das empresas - só sobrevivem com decisões políticas dos Estados [...]". Desta forma, o fundo público torna-se sujeito de disputas de poder e de recursos, dando nitidez à luta de classes no âmbito do Estado.

Cruz deixa bem claro que desenvolvimento econômico não é sinônimo de desenvolvimento humano. A cultura produtiva e política da região reproduzem fatores de concentração.

O grupo de poder hoje dominante no plano político-administrativo, à escala local, não necessita de desenvolvimento econômico para se reproduzir e manter o domínio, pois tem os royalties para serem utilizados para o clientelismo que rende votos. Alguns componentes políticos fundamentais da estratégia de dominação das elites tradicionais da 'era do açúcar', de caráter autoritário e conservador, sobrevivem, apropriados, atualizados e acrescidos de novos elementos e atributos, pelos grupos dominantes atuais, o que explica, em parte, a convivência, no Norte Fluminense, entre atividades econômicas estratégicas no plano nacional, e padrão subdesenvolvido da socioeconomia local. (2011, s/p. - grifos no original)

\section{Mercado de trabalho e elementos introdutórios para a análise da precariedade salarial}

Optamos por demarcar historicamente a análise a partir do ano de 1990 por compreender este intervalo de tempo (1990 - 2010) como de fundamental importância para o capitalismo em escala mundial e nacional e para Macaé de forma particular. Este período foi marcado por grandes transformações na esfera produtiva, financeira e política, a saber: crise do capital, rearranjos na reestruturação produtiva, como a flexibilização dos contratos de trabalho, a eleição de um governo de esquerda no país.

Em 1995 é implantada no Brasil uma "Reforma Gerencial do Aparelho do Estado", que traz rebatimentos diretos na organização da PE- 
TROBRAS. É com esta "contrarreforma" (BEHRING, 2003) que o Estado constrói condições ideológicas, políticas e materiais para a implantação definitiva do neoliberalismo e junto com ele a flexibilização dos contratos e relações de trabalho (inclusive no seu interior). Este ideário é coroado com estratégias de privatização de empresas estatais e terceirização da força de trabalho e serviços no âmbito do Estado. (SIRELLI, 2008).

É neste contexto de discurso e práticas "antiestatais" que a PETROBRAS, em 1997, perde o monopólio de exploração e produção do petróleo, intensificando a chegada de empresas ligadas ao setor petroquímico, principalmente de médio e pequeno porte (PAGANOTO, 2008). Esta miríade de novas empresas tem como norte a licitação de projetos, acompanhado da contratação temporária, terceirizada, flexibilizada de sua força de trabalho. As novas modalidades flexíveis de contrato previstas pela CLT terminam por degradar o trabalho e o trabalhador tanto no que diz respeito às condições objetivas de vida e trabalho, como a sua subjetividade enquanto classe. Neste ínterim também é relevante destacar a discussão em torno da exploração de petróleo em águas ultra-profundas, no intervalo de rochas que se estende por baixo de uma extensa camada de sal (daí a denominação de "pré-sal"). O "Pré-sal" projeta uma expectativa cada vez maior em termos de demanda do mercado de trabalho, tanto em tecnologia, quanto de profissionais capacitados. "[...] além da exploração específica da região do pré-sal e do segmento produtivo de petróleo e gás, inúmeros setores serão estimulados, como a indústria naval, a metalúrgica, a de construção civil e a prestação de serviços" (MACAÉ OFFSHORE, 2011), afirma sobre Macaé um sócio-diretor de uma empresa responsável pela área de training no Brasil, explicitando uma possibilidade de expansão do mercado de trabalho e de novas contratações de força de trabalho na cidade.

Esta realidade não é diferente em Macaé, e mais especificamente na PETROBRAS, como os dados recolhidos em 2002 e revelados por Cruz (2011, s/p.)

Os empregos diretos na Petrobras somam 6.900 e nas prestadoras de serviço, cerca de 28.000, num total de 34.900 empregos diretos. São 3.500 empresas fornecedoras, sendo que 1.800 delas fazem comércio eletrônico - o e-commerce - com a Petrobras. Das fornecedoras, 1.200 são microempresas. Os gastos com custeio, a maior parte efetivados na região, chegam a 5,38 bilhões de reais.

Carvalho e Rocha (2011) também apontam que, a partir de 2001, as empresas privadas superam a exploração de petróleo, por consequência de uma reestruturação tecnológica na PETROBRAS, que ocasiona de uma só vez a flexibilização das relações de trabalho, a diminuição do emprego direto e o aumento da força de trabalho terceirizada e subcontratada. Pela tendência do mercado de trabalho, acreditamos que o número de trabalhadores contratados diretos da PETROBRAS diminuiu ainda mais desde 
2002, reforçando a tese de uma nova precariedade do trabalho na região, expressa pelo aumento de empregos formais, entretanto, terceirizados e com características de flexibilização e precarização dos contratos, bem como pela precarização e intensificação do trabalho. Em termos cabais, as características da reestruturação produtiva, da acumulação flexível de capital se fazem presentes na região, sendo uma delas a "nova" precariedade salarial.

Segundo Alves (2011, p. 1), há uma "construção da nova condição salarial que emerge a partir da reestruturação produtiva e das novas modalidades especiais de contrato de trabalho flexível do mercado de trabalho brasileiro". Compartilhamos da tese defendida pelo autor quando este diz que emerge uma nova precariedade salarial, "entendida como sendo a condição salarial de novo tipo e a configuração de novo trabalhador coletivo", mais flexível, fragmentado e heterogeneizado - e com menores custos para as empresas. Reforçamos que, em nossa concepção, a palavra "nova" não conota o abandono da perspectiva de classe, mas ilustra que antigas formas de exploração e precarização do trabalho se sobrepõem a novas tendências que vem se esboçando no plano das relações de trabalho desde os anos 1970: flexibilização, terceirização, heterogeneização, precarização. Se até então a precariedade do trabalho estava quase sempre associada ao emprego informal, agora é possível afirmar a existência desta "nova" precariedade salarial, referente às modalidades contemporâneas de emprego formal, como o emprego temporário, flexível e desprovido de proteção previdenciária, por exemplo. Isso não implica que a antiga precariedade salarial dos empregos informais tenha se esvaído; somente agregase a ela esta novidade histórica, a massiva precarização do emprego formal, que advém dos tempos de reestruturação produtiva e de seu par político, o neoliberalismo.

Alves (2011) ainda defende que, para apreender a dinâmica desta nova precariedade, os processos de trabalho reestruturados são insuficientes; é necessário senão conhecer, entender e refletir acerca do mercado de trabalho flexibilizado como ponto de partida do trajeto que nos conduz à plena apreensão destes processos históricos. Diante desta necessidade, expomos a seguir os dados extraídos da RAIS, sintetizados e analisados pelos integrantes da pesquisa, acerca do mercado de trabalho formal em Macaé.

A partir de 1990, o que se observa é o crescimento vertiginoso dos vínculos empregatícios, em geral na cidade de Macaé: 22522 em 1990, 21467 em 1994, 31463 em 1998, 56521 em 2002, 85297 em 2006 e 115775 em 2010. Esta expressiva expansão é observável no Gráfico 1 apresentado.

Este crescimento não se observa nem no estado do Rio de Janeiro e sequer no Brasil durante o mesmo período. No Brasil, no mesmo período, o crescimento foi de 90\% (23.198.656 vínculos em 1990 e 44.068 .355 
Gráfico 1 - Total de vínculos empregatícios: Macaé, 1990 - 2010.

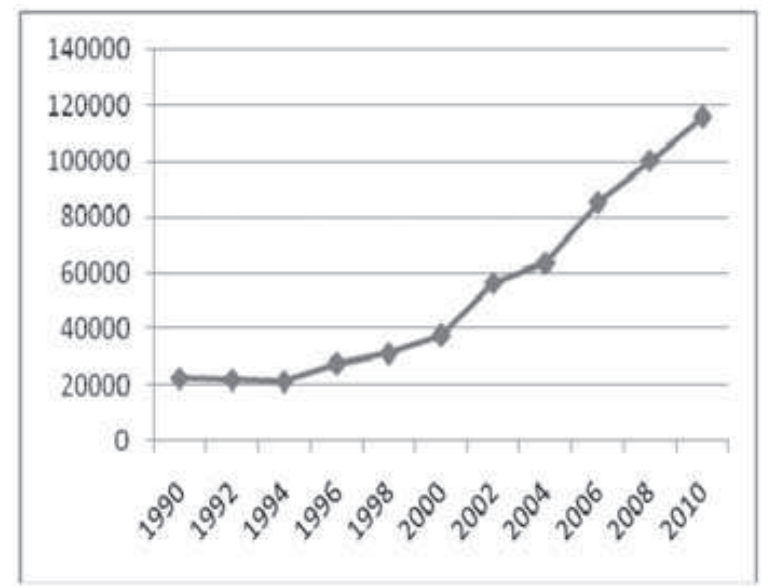

Fonte: RAIS/MTE - Elaboração: pesquisa "Trabalho, reestruturação do capital e mercado de trabalho em Macaé".

em 2010), no estado do Rio de Janeiro foi de 43,7\% (2838975 em 1990, 4.080.082), enquanto que em Macaé a variação foi de $414 \%$.

Uma das explicações para tal fenômeno pode ser aqui sintetizada: o dinamismo trazido pela instalação da PETROBRAS em Macaé, na década de 1970, acompanhado pela descoberta de novas jazidas de petróleo, inclusive com a novidade recente das jazidas de pré-sal, o que possibilita ao capital a sua exploração lucrativa. É de se notar, no mesmo Gráfico 1, o aumento exponencial que se apresenta a partir do ano de 2002, uma vez que os dados deste ano já contabilizam os vínculos relativos à iniciativa privada, dada a quebra do monopólio da Petrobras em 1997. Assim, os trabalhadores empregados desta data em diante já significam a possibilidade de valorização do capital de tipo puro, com a mais-valia produzida sendo apropriada privadamente.

O setor que mais cresceu o número de vínculos foi o de serviços, como se vê nos dados expostos na Tabela 01.

No entanto, não é um fato excêntrico ao movimento do capital contemporâneo este tamanho conquistado pelos serviços. Chesnais (1996, p. 185) argumenta que determinados fatores são capazes de explicar este processo: os grupos industriais avançam rumo aos serviços "ciosos de manter sua ascendência sobre certas importantes atividades de serviços, complementares às suas operações centrais". Ou em termos mais precisos,

Visto sob o ângulo das necessidades do capital concentrado, o duplo movimento de desregulamentação e de privatização dos serviços públicos constitui uma exigência que as novas tecnologias (a teleinformática, as 'infovias') vieram atender sob medida. Atualmente, é no movimento de transferência, para a esfera mercantil, de atividades que até então eram estritamente regulamentadas ou administradas 
Tabela 01 - Total de vínculos empregatícios, segundo setor de atividade: Macaé, 1990-2010.

\begin{tabular}{|c|c|c|c|c|c|c|c|c|c|c|c|c|}
\hline $\begin{array}{c}\text { Setor } \\
\text { IBGE }\end{array}$ & 1990 & 1992 & 1994 & 1996 & 1998 & 2000 & 2002 & 2004 & 2006 & 2008 & 2010 & $\begin{array}{c}\text { Variaçāo } \\
(\%)\end{array}$ \\
\hline Extr. mineral & 7952 & 7968 & 5267 & 7637 & 6034 & 4542 & 11451 & 13408 & 18496 & 22562 & 26786 & 236,80 \\
\hline Ind. transf. & 2211 & 1380 & 1981 & 2097 & 2341 & 2735 & 5050 & 6490 & 8869 & 12145 & 14254 & 544,68 \\
\hline Serv ind up & 434 & 425 & 439 & 316 & 93 & 83 & 444 & 527 & 320 & 293 & 612 & 141 \\
\hline Const. civil & 1425 & 1535 & 1627 & 2639 & 1816 & 4470 & 8187 & 7121 & 10173 & 12518 & 7559 & 430,50 \\
\hline Comércio & 2522 & 2188 & 3046 & 3826 & 4898 & 5170 & 7367 & 8228 & 9421 & 11898 & 14440 & 472,60 \\
\hline Serviços & 6142 & 6143 & 6599 & 8058 & 12932 & 17272 & 20068 & 23905 & 30862 & 35786 & 43148 & 602,50 \\
\hline Adm. Públ. & 1520 & 2142 & 2220 & 2881 & 2947 & 3291 & 3571 & 3543 & 6736 & 7507 & 8527 & 461 \\
\hline Agropec. & 316 & 294 & 288 & 305 & 402 & 406 & 383 & 460 & 420 & 450 & 449 & 42 \\
\hline Total & 22522 & 22075 & 21467 & 27759 & 31463 & 37969 & 56521 & 63682 & 85297 & $1 E+05$ & 115775 & 414 \\
\hline
\end{tabular}

Fonte: RAIS/MTE - Elaboração: Pesquisa "Trabalho, reestruturação do capital e mercado de trabalho em Macaé".

pelo Estado, que o movimento de mundialização do capital encontra suas maiores oportunidades de investir. A desregulamentação dos serviços financeiros num primeiro tempo; depois, nos anos 80, o início da desregulamentação e privatização dos grandes serviços públicos (em particular, os transportes aéreos, as telecomunicações e os grandes meios de comunicação de massas) representam a única nova fronteira aberta para o IED [investimento externo direto], sobre a base das atuais relações entre países e entre classes sociais. Enquanto o setor manufatureiro entra em choque com o aumento brutal do desemprego, com a marginalização do comércio exterior em muitos países e com a repartição desigual do poder aquisitivo, atividades como as indústrias multimídias são as únicas que oferecem possibilidades de expansão. (CHESNAIS, 1986, p. 186).

Isto é, a desregulamentação e a privatização dos serviços criaram o palco ideal para este avanço do capital que se vê nos dados de Macaé. Deste modo, estes mesmos dados de Macaé significam uma particularização de um movimento mais geral, a saber: o setor de serviço demonstrando-se como um espaço para a valorização do capital, principalmente com a saída do Estado.

Ainda com base na Tabela 01, que trata dos vínculos em geral por setor de atividade econômica, há que se abrir um parêntese sobre o crescimento da construção civil. Segundo os autores Monte, Rodrigues da 
Silva e Gonçalves (2011), este comportamento é mais ou menos uniforme em todo país. As explicações mais gerais para este fenômeno dizem respeito a políticas do governo federal na esfera da habitação, investimento em obras públicas, e elevação da renda das classes mais pauperizadas. É preciso acrescentar ainda que a construção civil se torna uma área bastante rentável para a exploração capitalista. Uma explicação de cunho mais particular é o crescimento da população da cidade de Macaé, que, como vimos, aumentou em 56\% nos últimos dez anos.

No concernente ao grau de instrução dos trabalhadores, podemos ver que é preponderante o número de trabalhadores cuja formação é relativa ao ensino médio completo, aumentando de 2.374 em 1990 para 66.254 em 2010. Para que se faça um comparativo, os trabalhadores com ensino superior vão de 2.183 em 1990 para 18.579 em 2010. Percentualmente, em face do total de trabalhadores, teríamos $16 \%$ com ensino superior, ao lado de 57,12\% com ensino médio. Trata-se de uma diferença que salta aos olhos, que se explica em parte pela exigência fundamentalmente técnica das atividades relacionadas ao extrativismo mineral.

O número de trabalhadores com o ensino médio incompleto sobrepunha-se aos demais em 1990: eram 49,6\% do montante empregado no extrativismo mineral (sendo 3.944 em números absolutos). Naquele ano, os de ensino médio completo eram insignificantes, contabilizando somente $1,4 \%$ (114 trabalhadores). Esta curva se inverte diametralmente em 2010: os trabalhadores de ensino médio incompleto são 480, representando 1,8\%, e os de ensino médio completo figuram em 63,4\% (16.979 trabalhadores). Novamente como comparativo, nota-se a estatística quanto aos de ensino superior: eram em 1990 em 1.544, representando 19,4\% do total, e em 2010 são 6.408, representando $24 \%$ do total, o que não implica um alto crescimento relativo de trabalhadores com ensino superior desde 1990.

Ainda no tema da instrução dos trabalhadores, outro dado ilustra certos aspectos da questão. Segundo o IBGE, em 2009, existiam 204 escolas entre públicas e privadas. Desta quantidade, apenas $12 \%$ eram de ensino médio, precisamente a instrução requerida em maior parte pelo extrativismo mineral. As matrículas no ensino fundamental somavam 30.890 alunos (70,7\% do total), enquanto que as matrículas no ensino médio totalizavam 6.549 alunos (15\% do total), indicando que a maioria dos egressos do ensino fundamental não cursa o ensino médio em Macaé. Resta uma reflexão: onde se qualifica esta força de trabalho que se insere no mercado de trabalho formal de Macaé? A hipótese plausível é a de que esta força de trabalho já aporta em Macaé com a qualificação necessária, adquirida em sua região de origem.

Estes dados nos revelam o incremento da heterogeneidade da classe trabalhadora, uma característica presente nos países em que o capital atravessou o processo de reestruturação produtiva. Antes de verificar os dados, leiamos o que nos escreve Antunes: 
Estas mutações [da reestruturação produtiva] criaram, portanto, uma classe trabalhadora mais heterogênea, mais fragmentada e mais complexificada, dividida em trabalhadores qualificados e desqualificados, do mercado formal e informal, jovens e velhos, homens e mulheres, estáveis e precários, imigrantes e nacionais, etc., sem falar nas divisões que decorrem da inserção diferenciada dos países e de seus trabalhadores na nova divisão internacional do trabalho. (ANTUNES, 2001).

Os dados exibem estatisticamente os resultados deste processo de fragmentação da classe trabalhadora que Antunes menciona acima. Em números absolutos, tínhamos em 1990 o emprego de 18.235 homens e 4.287 mulheres. Em 2010, são 85.043 de homens e 30.732 de mulheres no total. Isto quer dizer um aumento relativo maior para o emprego de mulheres: a contratação de homens aumentou em 366,3\% e a contratação de mulheres foi de $661,9 \%$. Ainda que, em termos absolutos, os homens sejam maioria, as mulheres indicam um aumento relativo maior.

Analisando o número de vínculos de mulheres no Brasil, no estado do Rio de Janeiro e em Macaé, percebemos que o percentual em Macaé $(26,5 \%)$ é muito inferior ao país $(41,6 \%)$ e ao estado $(40,2 \%)$. Surge o questionamento: Onde se insere esta força de trabalho feminina? Estariam estas mulheres inseridas no mercado informal? A cultura machista da região, bem como o perfil de postos de trabalho nos setores de extrativismo mineral e construção civil (tipicamente masculinos), tem alguma influência nesta baixa porcentagem de inserção de mulheres no mercado de trabalho? A existência de poucas creches públicas influencia negativamente, de forma que as mulheres não têm condição de inserção no mercado formal? Questões instigantes, mas que só poderão ser respondidas com pesquisas mais aprofundadas sobre a realidade do trabalho em Macaé.

Outros estudos apontam para este crescimento da parcela feminina da força de trabalho atentando para o aspecto precário que acompanha este crescimento

A participação feminina no mercado de trabalho aumentou, tanto no setor formal quanto nas atividades informais, com especial incremento do emprego no setor de serviços. Entretanto, [...] tal aumento foi acompanhado da precarização e da vulnerabilidade crescente dos novos empregos. Com muita frequência, trata-se de ocupações mal remuneradas, desvalorizadas socialmente e com possibilidade quase nula de promoção e de carreira, além de amparadas por direitos sociais frequentemente limitados ou inexistentes. (HIRATA, 2009, p. 149).

Esta citação demonstra que a força de trabalho feminina é geralmente fruto de maior exploração por parte do capital. Se compararmos historicamente com os homens, as mulheres são objeto de extração de mais-valia com mais intensidade. 
O crescimento de empresas multinacionais em Macaé reafirma e intensifica esta tendência de precarização da força de trabalho feminina. No mesmo estudo, Hirata (2009, p. 146-147) pondera que há nas empresas mundializadas uma inserção diferenciada dos homens e das mulheres nos processos de trabalho destas. Quanto a isto, as "condições de trabalho e de remuneração [das mulheres] são claramente menos favoráveis nas filiais dos grupos internacionais situadas nos países do sul".

Uma análise feita por Oliveira (2003, p. 136) acerca do mercado de trabalho de 1981 a 1999 aponta para a existência de um "hiato salarial de gênero", que tende a aumentar com o aumento da proporção feminina na ocupação. Ou seja, aumenta-se o assalariamento feminino na mesma medida em que se aumenta o abismo salarial se comparado com os homens. Esta fórmula é verificável em Macaé.

Quanto à remuneração, pode-se verificar a distinção elaborada por Antunes (2002) entre periferia e centro da força de trabalho. A periferia da força de trabalho diz respeito aos trabalhadores com baixa remuneração e pouca qualificação, temporários, com alta rotatividade, etc., ao passo que o centro refere-se a trabalhadores com qualificação elevada, altos salários e estáveis; o que esta situação evidencia é a diferenciação interna à classe trabalhadora, o que acentua os conflitos internos a ela e obstaculiza a formação da consciência de classe, uma vez que o trabalhador não se reconhece no outro. É precisamente o setor do extrativismo mineral que engloba a grande parte dos trabalhadores do centro da força de trabalho no que diz respeito à remuneração: em 2010, aqueles que ganham mais de 20 salários míninos são 8.544 trabalhadores, representando um percentual de 73,7 em face do total; os trabalhadores que ganham de 1 a 1,5 salário mínimo no extrativismo mineral são inferiores a 0,5\% do total. No geral, relacionando todas as áreas, o que prepondera são os trabalhadores que recebem de 2 a 3 salários mínimos e de 1 a 1,5 salário mínimo. Isto indica que, apesar do crescimento do emprego formal, os salários são baixos para boa parte dos trabalhadores, com a exceção à regra representada pelo extrativismo mineral. Em 2010, são 46.667 trabalhadores que recebem menos de 3 salários mínimos, equivalendo a $40 \%$ dos vínculos. A metade dos trabalhadores de Macaé está na faixa de remuneração abaixo de 4 salários no ano de 2010.

Esta diferença na remuneração dos trabalhadores se reflete no espaço urbano, na favelização da cidade de Macaé, por exemplo. A informação de que a metade dos trabalhadores de Macaé recebe até 4 salários desconstrói o fetiche da alta remuneração dos empregos na cidade. Esta alta remuneração é o caso peculiar do extrativismo mineral e, diante dos dados, não pode ser generalizada para as demais categorias.

Enfim, temos os dados relativos à carga horária que indicam que a parcela maior dos trabalhadores nas atividades em geral possui um intervalo de trabalho entre 41 a 44 horas semanais. Segundo os dados fornecidos pelas empresas ao ministério do trabalho, não consta nenhum trabalhador 
com carga horária superior a 45 horas semanais. Assim, a exploração da mais-valia absoluta, isto é, aquela que se dá com o simples aumento da jornada de trabalho, está relativamente impossibilitada. Entretanto, a reestruturação produtiva permite novas modalidades de exploração da mais-valia relativa (a que se dá com o crescimento relativo da fração da mais-valia frente ao investimento em capital variável, permanecendo a jornada de trabalho inalterada), especialmente graças à inovação tecnológica implantada no processo produtivo e ao aumento exponencial do exército industrial de reserva. Vale ressaltar também a possibilidade de subnotificações ao fornecer os dados ao Ministério do Trabalho e Emprego (MTE). É sabido que muitos trabalhadores têm regime de trabalho especial, os chamados "embarcados", que trabalham sob regime de 14 dias embarcados. Esta modalidade não é contemplada pela RAIS.

\section{Considerações Finais}

Com base nos argumentos apontados na pesquisa, pode-se dizer que trouxe rebatimentos para o país a globalização do capital internacional, que inclui também como característica a reestruturação produtiva, modificando de forma radical as bases produtivas e sua organização de forma a terceirizar os serviços prestados, na perspectiva de redução de custos, exploração da força de trabalho e obtenção de maiores lucros. A globalização que, conforme Costa (2008), é conduzida pelas transnacionais, transforma o mundo em uma reserva de força de trabalho barata a seu inteiro dispor. E isto, aliado às idéias neoliberais conduzidas pelos ditames de instituições internacionais hegemônicas - como Fundo Monetário Internacional (FMI) e Banco Mundial -, acrescido do processo de contrarreforma do Estado ocorrido no Brasil no período analisado, tende cada vez mais a precarizar o trabalho, trazendo da mesma forma diferenciações hierárquicas de grande tamanho no mundo do trabalho, como exemplo dentro da PETROBRAS, e, portanto, enfraquecendo o poder de organização dos trabalhadores. Além disto, as privatizações e a entrada de empresas estrangeiras no país permitem que se amplie a subordinação aos demais países desenvolvidos.

A cidade de Macaé atualmente conta com um enorme contingente de empresas multinacionais, e nestas é empregado grande número de força de trabalho com modalidades de contrato inferiores aos empregados diretos da PETROBRAS, sendo que boa parte se constitui como temporários, mais flexíveis e ausentes ou de reduzidas garantias (o que chamamos aqui de "nova" precariedade salarial). A cidade está integrada ao modelo econômico do país, de desenvolvimento desigual e combinado, destacando-se contrastes e disparidades regionais e sociais. O dinamismo econômico, verificável pelo crescimento de vínculos formais de trabalho superiores às taxas estaduais e nacionais, não suprime as imensas disparidades ociais. 
Através dos resultados de pesquisas mencionadas ao longo do artigo, é possível afirmar que, mesmo com a entrada dessas empresas que aumentaram o nível de empregos formais, a cidade não se preparou para isso. Grande parte da força de trabalho que obtém empregos com altos salários, com garantias que permitem uma qualidade de vida, geralmente vem de outros lugares, e isso é perceptível pelo crescimento dos níveis de migração, ainda que não seja somente destes. $\mathrm{O}$ fato é que mesmo com o crescimento dessa miríade de multinacionais, embora houvesse alta circulação de capital na cidade e crescimento da oferta de empregos advindos de todo esse processo, o mesmo não representou uma melhoria na qualidade dos vínculos empregatícios.

Os dados da pesquisa demonstram justamente esta realidade: em geral, os vínculos empregatícios em Macaé se precarizam, os salários mantêm-se baixos (o que se ilustra pelo número de $50 \%$ dos trabalhadores com salário abaixo de 4 salários mínimos), a exploração da força de trabalho feminina e demais sintomas da "nova" precariedade salarial. Observa-se uma recuperação e expansão das atividades econômicas com efeito positivo sobre os níveis de emprego, mas não de salários. O comportamento do mercado de trabalho em Macaé é distinto do estado e do Brasil ao se levar em consideração o gênero, já que o crescimento de vínculos femininos é pequeno, se comparado a outras pesquisas de mercado de trabalho, bem como ao estado e ao país. A parcela de trabalhadores que se situam no extrativismo mineral, vinculados à indústria do petróleo, aparece como exceção à regra, já que são os trabalhadores mais bem remunerados - mas que mantém a baixa inserção da força de trabalho feminina. Esta exceção exibe às claras a diferenciação interna à classe trabalhadora, que se intensifica com o processo de reestruturação produtiva particularizado em Macaé.

Constatamos ainda a existência de três momentos importantes na dinâmica do mercado de trabalho em Macaé: a 1a fase que vai até 1978, ano que Macaé passa a sediar a PETROBRAS, acarretando a expectativa de geração de postos de trabalho. Neste período, predominava o trabalho focado na agricultura, na pesca e no turismo. A $2^{\text {a }}$ fase, que vai do início da década de 1980 até fins da década de 1990, quando há um crescimento tímido dos vínculos formais. A $3^{3}$ fase tem início em fins da década de 1990, se estende até os dias de hoje, e caracteriza-se pelo salto expressivo nos vínculos formais, principalmente nos setores de serviços e no extrativismo mineral. Este salto pode ser explicado pela recuperação da economia brasileira, com mudanças importantes no mercado de trabalho. Em Macaé, teve impacto a quebra do monopólio da exploração do petróleo pela PETROBRAS, o que ajuda a explicar o salto do número de vínculos no setor de extrativismo mineral.

Nossa indagação principal é o que tem significado este aumento dos vínculos formais para os trabalhadores de Macaé. Borges (2011), Alves 
(2011) e Antunes (2010) coadunam com nossas análises de que este aumento nos vínculos formais não tem sido sinônimo de aumento de qualidade nestes postos de trabalho, e usam a precarização do trabalho como explicativo deste momento histórico de exploração do capital, uma vez que, em tempos de degradação do trabalho, estamos defronte a "outras modalidades e modos de ser da precarização", rumo a uma precarização estrutural do trabalho (ANTUNES, 2010, p. 17) e a uma "nova precariedade salarial" (ALVES, 2011).

Esta é uma análise também realizada por Borges:

[...] o novo período de expansão, mesmo que marcado pelo expressivo crescimento dos vínculos formalizados funda-se no patamar rebaixado de exploração salarial que resultou da reestruturação produtiva e, por não romper com os mecanismos estruturais de precarização acaba por não sinalizar com horizontes seguros e protegidos para os que vivem do trabalho. (BORGES, 2011, p. 111)

É importante enfatizar que o aumento de postos de trabalho formais, no entanto, não significa diminuição ou extinção do trabalho informal e do desemprego - são faces de uma mesma necessidade o capital, que cumpre, inclusive, "papel ativo no ciclo de valorização do valor, especialmente pela criação de um enorme excedente de força de trabalho que subvaloriza quem se mantém no universo do trabalho assalariado". (ANTUNES, 2010, p. 18).

O movimento que se observa no mundo é uma constante e cada vez mais acirrada deterioração das condições de trabalho, independente da forma de emprego - formal, informal, com vínculos estáveis ou precários.

É imprescindível dar luz e intensificar as análises sobre a categoria precariedade, analisando não só as relações de trabalho, mas também as experiências vividas pelos trabalhadores e suas famílias. Indicamos um leque de possibilidades de análise para estudos futuros, e enfatizamos a necessidade de se aprender a maneira como os sujeitos são atingidos pela precarização estrutural do trabalho.

A análise do mercado de trabalho tornou-se decisiva e premente para compor um quadro do desenvolvimento do capitalismo brasileiro, da Região Norte Fluminense e, por fim, de Macaé. Os resultados apontados aqui evidenciam e reforçam a necessidade de se estabelecer políticas publicas de emprego, municipais e regionais, que norteiem o desenvolvimento regional e local, mantendo não apenas o dinamismo econômico e os vínculos, mas preocupada com as condições de trabalho e remuneração. Esta indicação traz à tona a importância do debate sobre o padrão de desenvolvimento a ser seguido e o lugar de Macaé na divisão regional e nacional do trabalho. Ilumina também a necessária e urgente tarefa de uma fiscalização do uso dos recursos públicos na cidade, inclusive os advindos da exploração do petróleo (royalties). 
Um dos maiores desafios do município de Macaé é não subordinar a política social e de trabalho à política econômica. Só assim haverá realmente uma redução das assimetrias na relação capital-trabalho, fazendo valer as instâncias de regulação pública dos contratos de trabalho.

Nesta perspectiva, é preciso fortalecer espaços de participação pública e democrática, como Conselhos de direito, movimentos sociais, bem como os diversos sindicatos que existem na cidade. Esta representação sindical, entretanto, precisa se demonstrar forte, autônoma, democrática, representativa dos trabalhadores, com direções eleitas pelos trabalhadores.

Até o momento, ao analisar os determinantes da configuração do capitalismo na região, podemos afirmar que, apesar de ter se tornado a capital brasileira do petróleo, como demonstram os altos índices de emprego e crescimento da cidade, a mesma está longe de ser o eldorado, a "terra prometida", como acreditam muitos que a procuram com a expectativa de melhores condições de vida e trabalho. Com todas as transformações que acometem as esferas do trabalho, do Estado, de degradação do humano e de intensificação das expressões da questão social, a mesma se aproxima muito mais de um "oásis da precarização do trabalho", e traz contundentes implicações para os níveis de emprego e para a qualidade dos vínculos de trabalho, que agora dizem respeito também ao emprego formal. 


\section{Referências}

ALVES, G. As intermitências da contingência: a experiência da nova precariedade salarial no Brasil. Bolsa Produtividade em Pesquisa/CNPq 20082010. Disponível em: <http://www.giovannialves.org/PP2008.swf>. Acesso em: 25 mar. 2011.

ANTUNES, R. Adeus ao trabalho? Ensaio sobre as metamorfoses e a centralidade do mundo do trabalho. São Paulo: Cortez, 2001.

. Os modos de ser da informalidade: rumo a uma nova precarização estrutural do trabalho? Revista Praia vermelha. Rio de Janeiro. v. 20. n.1. 2010.

BEHRING, E.R. Brasil em contra-reforma: desestruturação do Estado e perda de direitos. São Paulo: Cortez Editora, 2003.

BORGES, Â. Mercado de trabalho da RMS: duas décadas de transformações. Anais do XII encontro nacional da Associação brasileira de estudos do trabalho. João Pessoa: ABET, 2011.

CARLI, R. Educação e cultura na história do Brasil. São Paulo: IBPEX, 2010. CARVALHO, A.M.; ROCHA, C. N; FREITAS, B.V. Perfil socioeconômico do trabalhador formal no setor de petróleo em Macaé. Disponível em: <http:/ /www.portalabpg.org.br/PDPetro/3/trabalhos/IBP0232_05.pdf>. Acesso em: 05 jan. 2011.

CHESNAIS, F. A mundialização do capital. São Paulo, Editora Xamã, 1996. CORRÊA BORBA, R.; MOURA OLIVEIRA, V.; SILVA NETO, R. A influência do petróleo na dinâmica econômica das cidades: um estudo comparativo entre Macaé (Brasil) e Aberdeen (Reino Unido). II Jornada nacional de produção científica em educação profissional e tecnológica. São Luiz/MA, 2007.

CRUZ, J.L.V. Emprego, crescimento e desenvolvimento econômico: notas sobre um caso regional. Disponível em: <http://www.senac.br/INFORMA TIVO/ BTS/291/boltec291c.htm>. Acesso em: 06 jan. 2011.

. Construção e desconstrução da região Norte Fluminense entre 1970 e 2000. Tese (Doutorado) - Instituto de Pesquisa e Planejamento Urbano e Regional da Universidade Federal do Rio de Janeiro. Rio de Janeiro. (IPPUR/ UFRJ), Rio de Janeiro, 2003.

GLOBOTV. BOPE vai ficar por tempo indeterminado nas comunidades Nova Holanda e Malvinas. Bom Dia Rio, 25/03/2011. Disponível em: <http:/ /globotv.globo.com/rede-globo/bom-dia-rio/v/bope-vai-ficar-por-tempo-in determinado-nas-comunidades-nova-holanda-e-malvinas/1468842/l>. Acesso em: 25 mar. 2011. 
HIRATA, H. Globalização e divisão sexual do trabalho em uma perspectiva comparada. GUIMARAES, N. A. HIRATA, H. SUGITA, K. (Orgs.) Trabalho flexível, emprego precários? Uma comparação Brasil, França, Japão. São Paulo: EDUSP, 2009.

IAMAMOTO, M. V. Serviço Social em tempo de capital fetiche: capital financeiro, trabalho e questão social. 4 ed. São Paulo: Cortez, 2010.

LIMA, F.V.; SANTOS, M.P.; RODRIGUES, V.E.S. Estrutura produtiva e emprego formal no município de Macaé: transformações e novas tendências. In: 30. Congresso brasileiro de P\&D em petróleo e gás. Salvador, 2005. Disponível em: <http://www.portalabpg.org.br/PDPetro/3/trabalhos/IBP0353_05.pdf>. Acesso em: 06 jan. 2011.

MACAÉ OFFSHORE. Carreiras: a demanda por profissionais na era do présal. Disponível em: <http://www.macaeoffshore.com.br/capa/Materias.aspx? id=2382 >. Acesso em: 22 mar. 2011.

MONTE, P.A.; RODRIGUES DA SILVA, J.A.; GONÇALVES, M.F. A dinâmica do emprego na região nordeste no período 2000 a 2009. Anais do XII Encontro nacional da associação brasileira de estudos do trabalho. João Pessoa: ABET, 2011. v. 1

NETO, R. A influência do petróleo na dinâmica econômica das cidades: um estudo comparativo entre Macaé (Brasil) e Aberdeen (Reino Unido). II Jornada nacional de produção científica em educação profissional e tecnológica. São Luiz/MA, 2007.

PAGANOTO, F. Mobilidade e trabalho em Macaé/ RJ, a "capital do petróleo". Dissertação (Mestrado) - Programa de Pós-Graduação em Geografia da Universidade Federal do Rio de Janeiro. Rio de Janeiro: UFRJ/PPGG, 2008.

SILVA, E.T.; CAVENAGHI, S. Mercado de trabalho e diferenciais por sexo em Campos dos Goytacazes e Macaé. Disponível em: <http://www. abep.nepo.unicamp.br/encontro2006/docspdf/ABEP2006_522.pdf>. Acesso em: 05 jan. 2011.

SIRELLI, P.M. Terceirização na esfera pública estatal: estratégia (im)posta à Universidade Federal de Juiz de Fora. Dissertação (Mestrado) - Programa de Pós-Graduação em Serviço Social. Juiz de Fora, UFJF: 2008.

Recebido em 01 de outubro de 2012.

Aprovado para publicação em 14 de dezembro de 2012. 